\title{
Bio-Oil Extracted of Wet Biomass of the Microalga Monoraphidium sp. for Production of Renewable Hydrocarbons
}

\author{
Yordanka R. Cruz ${ }^{1}$, Gisel Ch. Díaz ${ }^{1}$, Viviane de S. Borges ${ }^{1}$, \\ Andreina Z. F. Leonett ${ }^{1}$, René G. Carliz ${ }^{1}$, Vinicius Rossa ${ }^{2 *}$, \\ Vitor M. E. S. Silva ${ }^{3}$, Carolina Vieira Viegas ${ }^{1}$, \\ Donato A. G. Aranda ${ }^{1}$, Luciano B. Oliveira ${ }^{3}$ \\ ${ }^{1}$ GREETEC Laboratory, Federal University of Rio de Janeiro (UFRJ), Rio de Janeiro, Brazil \\ ${ }^{2}$ GCAT Laboratory, Federal University of Uberlâdia (UFU), Rio de Janeiro, Brazil \\ ${ }^{3}$ Research Company Energetic (EPE), Rio de Janeiro, Brazil \\ Email: *vinnyrossa@gmail.com
}

How to cite this paper: Cruz, Y.R., Díaz, G.Ch., Borges, V.S., Leonett, A.Z.F., Carliz, R.G., Rossa, V., Silva, V.M.E.S., Viegas, C.V., Aranda, D.A.G. and Oliveira, L.B. (2019) Bio-Oil Extracted of Wet Biomass of the Microalga Monoraphidium sp. for Production of Renewable Hydrocarbons. Journal of Power and Energy Engineering, 7, 80-90.

https://doi.org/10.4236/jpee.2019.71005

Received: September 10, 2018

Accepted: January 22, 2019

Published: January 25, 2019

Copyright $\odot 2019$ by author(s) and Scientific Research Publishing Inc. This work is licensed under the Creative Commons Attribution International License (CC BY 4.0).

http://creativecommons.org/licenses/by/4.0/

\section{c) (i) Open Access}

\begin{abstract}
Renewable hydrocarbons refer to fuels consisting of hydrocarbons of 10 to 20 carbon atoms, produced from biomass, and free of oxygen. Hydrocracking, hydrodeoxygenation and hydrotreatment processes for the production of renewable hydrocarbons are described in the literature. Microalgae have been targeted in recent years to synthesize biomass that can be used in the production of biofuels, such as renewable hydrocarbons, biodiesel or ethanol second generation. In this context the lineage Monoraphidium sp. was selected from previous ecophysiological studies and its potential to produce lipids to develop this research related with the extraction of the bio-oil of the wet biomass of Monoraphidium sp. through heat treatment. Consecutively the bio-oil was used as raw material for the production of hydrocarbons through hydrocracking and hydrodeoxygenation processes (HDO) as: decarbonylation, decarboxylation, dehydratation, with in situ production of hydrogen from liquid-phase reforming of glycerol. The reactions were carried out under two different temperature conditions, $350^{\circ} \mathrm{C}$ and $300^{\circ} \mathrm{C}$, respectively, for $1 \mathrm{~h}$ and using ruthenium alumina catalyst $\left(\mathrm{Ru} / \mathrm{Al}_{2} \mathrm{O}_{3}\right)$. The results showed the bio-oil processing route at a temperature of $350^{\circ} \mathrm{C}$ promising for the production of hydrocarbons achieving a conversion of $81.54 \%$.
\end{abstract}

\section{Keywords}

Renewable Hydrocarbons, Hydrotreatment, Bio-Oil, Monoraphidium sp. 


\section{Introduction}

The Green Technologies Laboratory (GreenTec) has been working for the past five years on the development of closed microalgae culture systems and biodiesel production technologies using thermochemical routes for the processing of this raw material [1]. The researches carried out followed the concept of biorefinery (complete use of microalgal biomass producing biofuels and bioproducts).

The results obtained together with the aim of contributing to the consolidation of the production of a multiplicity of bioproducts from microalgae have motivated the interest of continuing to deepen in the development of technologies for the production of renewable hydrocarbons. Long-chain hydrocarbons have applications in the lubricant industry (in this case, biolubricant) and, mainly, "drop-in" fuels [2] [3].

One of the important requirements for renewable fuels are preferably drop-in, that is, similar biofuels from a chemical point of view to fossil fuels, that can be mixed directly to petrochemical analogues, being able to use the same infrastructure and not requiring adaptations in the engines. In this description, renewable diesel and aviation biokerosene (BioQAv) are included.

Renewable hydrocarbons refer to fuels consisting of hydrocarbons of 10 to 20 carbon atoms, produced from biomass, free of oxygen. The best known processes for converting bio-oil into renewable hydrocarbons are the Fischer-Tropsch reactions, from synthesis gas $\left(\mathrm{H}_{2}: \mathrm{CO}\right.$ mixture) produced by gasification of the bio-oil, hydrolysis process combined with hydrodeoxygenation processes (HDO) and hydrotreatment. The Fischer-Tropsch process, although well known, is not widely used because it is onerous and still uncompetitive, especially in Brazil, where other routes seem to be more viable [4].

The hydrolysis of triglycerides present in the bio-oil makes it possible to obtain fatty acids and glycerol, the reaction proceeds in stages, which occur simultaneously at different speeds. In hydrolysis reactions, the triglycerides are converted to diglycerides and monoglycerides and these into glycerol and fatty acids. All these reactions are reversible [5].

The fatty acids produced in the hydrolysis step may be decarboxylated by hydrodeoxygenation processes. Similar hydrodeoxygenation (HDO) processes for the production of renewable hydrocarbons are described in the literature [6] [7]. In these processes, oils, fats and bio-oil, basically constituted by triglycerides and fatty acids, molecules with high levels of oxygen, are subjected to high pressures of $\mathrm{H}_{2}$ and high temperatures, in the presence of metallic catalysts, promoting deoxygenation.

In 2006, Petrobras patented the product, known as H-Bio. In the developed process, oils and fats, together with the mineral oil, are subjected to the hydrotreatment unit at a pressure $>50 \mathrm{~atm}$, a temperature $>300^{\circ} \mathrm{C}$ in the presence of a catalyst obtaining a high quality diesel composed only of hydrocarbons [8].

In this context, this research is related to the extraction of the bio-oil of the humid biomass of Monoraphidium sp. through heat treatment. The bio-oil was 
then evaluated as a raw material for the production of hydrocarbons through hydrocracking and hydrodeoxygenation (HDO) processes such as decarboxylation, decarbonylation and dehydration, with in situ hydrogen production by liquid reforming of glycerol [9].

\section{Materials and Methods}

The wet biomass of the microalga Monoraphidium sp. used in the extraction of bio-oil for the production of hydrocarbons was cultivated in the pilot unit of UFRN-Natal in an open-pit system. Concentrated through the flocculation process, followed by centrifugation. Centrifugation was performed in the Pilot Unit of the Green Technologies Laboratory-GREENTEC of the EQ/UFRJ using Hitachi CR22N centrifuge at a speed of $8.000 \mathrm{rpm}$ for a time of 10 minutes.

Extraction of the bio-oil (apolar fraction present inside the microalgae cells), through the heat treatment reaction at $180^{\circ} \mathrm{C}$ for $1 \mathrm{~h}$, performed in Parr Instruments Inc. Model 4550 reactor, of the autoclave type made of stainless steel, of useful volume of five gallons and maximum working pressure of $3000 \mathrm{psi}$. It has a cooling system to ensure temperature control, agitation system and external heating mantle (Figure 1).

After the reaction the product obtained was allowed to stand for $20 \mathrm{~h}$ to observe phase separation. After the time, two phases, one upper liquid phase and one liquid/solid lower phase were observed. In both phases hexane and $10 \mathrm{wt} \%$ sodium chloride were added to increase polarity and thereby facilitate the extraction with hexane of medium polar hydrocarbons, such as fatty acids. Posteriorly, after $3 \mathrm{~h}$ the upper apolar phase (bio-oil) of light brown color was separated and washed to remove any salt residue. The Bio-oil extracted from both phases was mixed (Figure 2) and characterized by its physical-chemical properties (Relative Density at $25^{\circ} \mathrm{C}$, Kinematic Viscosity at $40^{\circ} \mathrm{C}$, Acidity Index, Iodine Index and Elemental Analysis), determination of fatty acid esters (\%) by gas chromatography, as also, was performed distillation simulated by ASTM D2887.

- Density relative to $25^{\circ} \mathrm{C}\left(\mathrm{kg} \mathrm{m}^{-3}\right)$

Density is the mass per unit volume at a specified temperature. Relative density
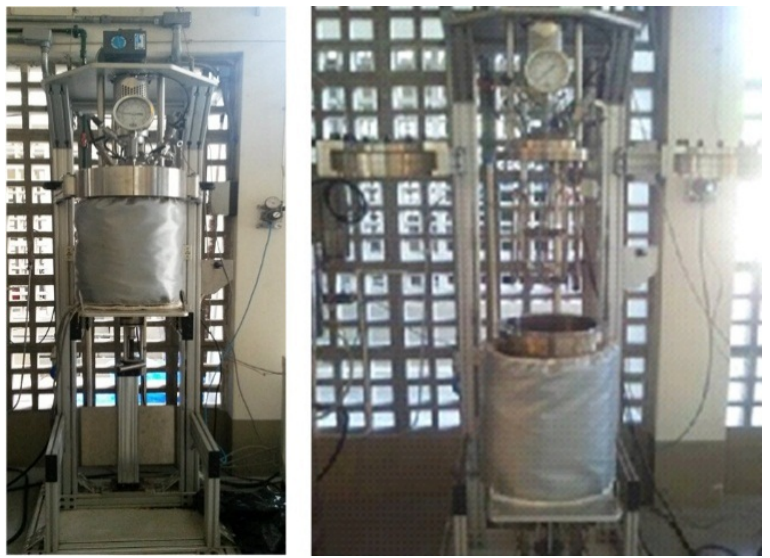

Figure 1. Parr Instruments Inc. Model 4550 Reactor. 


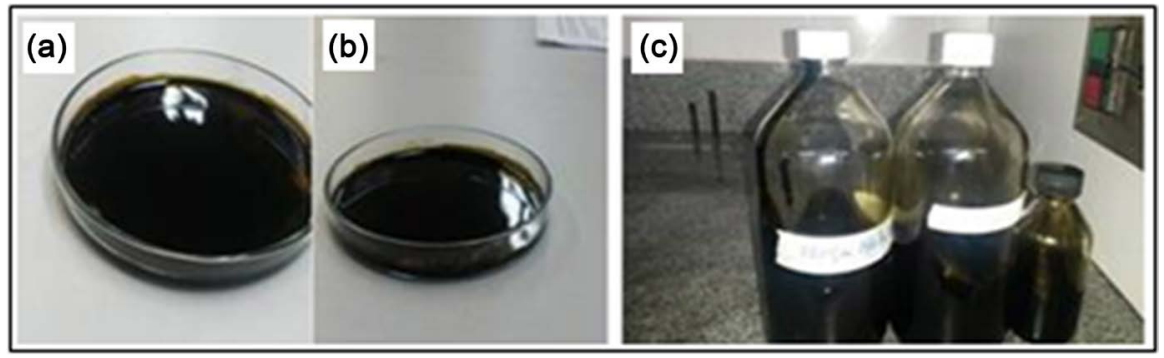

Figure 2. Bio-oil extracted from the phases: (a) upper liquid, (b) Liquid/solid bottom, after recovery of extractor solvent (hexane) and (c) Bio-oil extracted from both phases mixed.

or specific mass is the ratio of the mass of the sample to that of water per unit volume at an established temperature (in this case $25^{\circ} \mathrm{C}$ ). This method covers the determination of the density or relative density of petroleum distillates and viscous oils which can normally be handled as liquids at the test temperature between $15^{\circ} \mathrm{C}$ and $35^{\circ} \mathrm{C}$. Relative density was determined following ASTM D-1298.

- Kinematic viscosity at $40^{\circ} \mathrm{C}\left(\mathrm{mm}^{2} \cdot \mathrm{s}^{-1}\right)$

The method consists in measuring the time of a liquid volume flowing under gravity through the Cannon-Fenske viscometer in a $40^{\circ} \mathrm{C}$ thermostatic bath. Absolute viscosity is the resistance that every real fluid offers to the relative motion of any of its parts and kinematic viscosity is the ratio of its absolute viscosity to its specific mass, both being at the same temperature. Kinematic viscosity was determined following ASTM D-445.

- Acid index (mg KOH g ${ }^{-1}$ )

The acidity or free acidity index is expressed by the percentage of free fatty acids of a given product. Defined as the number of milligrams of potassium hydroxide required to neutralize free acids of 1 gram of the sample (Moretto and Fett, 1998). The acidity of an oil or fat, as well as the rancification states represents a very variable characteristic that depends on the state or condition of the lipid. The acid index was determined following AOCS (American Oil Chemists' Society) Cd 3d-63.

- Iodine content ( $g$ of $\mathrm{I}_{2} 100 \mathrm{~g}^{-1}$ )

It is the measure of the degree of unsaturation (double bonds) of an oil or fat and is expressed in terms of the number of grams of iodine absorbed per gram of the sample. Fixation of iodine or other halogens occurs in the ethylenic bonds of fatty acids. The iodine value was determined following the AOCS standard Cd $1-25$, using the Wijs reagent.

- Elemental analysis

The elemental composition of the bio-oil was determined at the Leopoldo Américo Miguez de Mello Research Center-CENPES of Petrobras. Carbon, hydrogen and nitrogen contents were determined using a LECO CHN-1000 equipment according to the ASTM D-5291 method, normally used for coals. Analysis of the sulfur content was performed on the SC-432 equipment, based on ASTM D-4239. Oxygen content was determined using ASTM D-5622, rec- 
ommended for solid or viscous samples.

- Determination of the methyl esters profile of fatty acids present in the extract For identification of the lipid profile of the extracted oil, it was necessary to convert these lipids to methyl esters in order to facilitate the identification of the components through gas chromatography.

In this initial stage a methanolysis of the lipid extract was carried out, according to the methodology described by $\mathrm{YOO}$ with modifications [10], using $2 \mathrm{~mL}$ of methanol and $5 \%$ of $\mathrm{HCL}$ at $75^{\circ} \mathrm{C}$ for 10 minutes in a Maria bath. This step was performed in a closed bottle to avoid evaporation.

Next, the phase containing the methylated fatty acids was separated with the addition of $2 \mathrm{~mL}$ of distilled water and $2 \mathrm{~mL}$ of hexane PA. The higher hexane phase was collected with an automatic pipette and transferred to a glass bottle, then placed in an oven at $60^{\circ} \mathrm{C}$ for solvent evaporation and concentration of the sample.

After the methanolysis, the percentage of fatty acid methyl esters was determined by Gas Chromatography using the EN 14103 method. For this purpose, the samples were diluted in heptane at the ratio of $0.05: 1(\mathrm{~m} / \mathrm{m}) .1 \mu \mathrm{L}$ of this sample was injected into the Shimadzu gas chromatograph, model GC-2014 with split/splitless Injector, flame ionization detector (FID), Carbowax $20 \mathrm{M}$ column (30 $\mathrm{m} \times 0.25 \mathrm{~mm} \times 0.25 \mu \mathrm{m}$ ), Quadrex brand, with the following conditions: column flow of $3 \mathrm{~mL} / \mathrm{min}^{-1}, 200^{\circ} \mathrm{C}$ isothermal, injector: $250^{\circ} \mathrm{C}$, detector: $250^{\circ} \mathrm{C}$, drag gas pressure of $1.9 \mathrm{~mL} / \mathrm{min}^{-1}$. The analyses were performed for $30 \mathrm{~min}$.

The qualitative identification of the fatty acid methyl esters (fatty acid profile,\%) is carried out by comparing the retention time of the constituents of the sample with a mixture consisting of 37 external patterns of methyl esters of fatty acids from Sigma (C4:0 - C24:0). The composition is determined by the percentage of the relative areas of each characteristic peak of fatty acid methyl ester (EMAG) with the total peak area of the chromatogram (normalization method).

\section{- Simulated distillation}

The sample was analyzed by simulated distillation in order to determine the initial and final boiling temperatures of the extracted bio-oil fraction and the yield of the main cuts. This analysis was performed at the Laboratory of Chromatographic Analyzes of CENPES-RJ following the ASTM D-2887 standard.

Production of renewable hydrocarbons from microalgae bio-oil: The hydrodeoxygenation and hydrocracking reactions of the bio-oil were carried out in a Parr reactor with a $600 \mathrm{~mL}$ volume, under two different temperature conditions 350 and $300^{\circ} \mathrm{C}$ respectively, $\mathrm{t}=1 \mathrm{~h}$ and using $5 \%$ alumina supported ruthenium catalyst $\left(\mathrm{Ru} / \mathrm{Al}_{2} \mathrm{O}_{3}\right)$. They were used $119 \mathrm{~g}$ of bio-oil, $10 \mathrm{wt} \%$ of the catalyst, $20 \mathrm{wt} \%$ glycerol and as a hydrolyzing agent distilled water (bio-oil:water ratio $=1: 1$ ).

The reduction of the $5 \% \mathrm{Ru} / \mathrm{Al}_{2} \mathrm{O}_{3}$ catalyst, before each reaction, was carried out with pure $\mathrm{H}_{2}$ at $40 \mathrm{~atm}$ of pressure, in the batch reactor itself, with a heating rate of $10^{\circ} \mathrm{C} \cdot \mathrm{min}^{-1}$ until reaching a temperature of $300^{\circ} \mathrm{C}$. After remaining at the maximum temperature $\left(300^{\circ} \mathrm{C}\right)$ for $1 \mathrm{~h}$ the system was cooled to room temperature. 
The organic fraction, produced in the reactions described above, was characterized while the acid value and iodine number and for the identification of the hydrocarbons formed were used in the Gas chromatography performed in comparison with the retention time of paraffinic hydrocarbon standards according to the methodology described below: $0.05 \mathrm{~g}$ of sample were dissolved in $2 \mathrm{~mL}$ of heptane. For analysis, $1 \mu \mathrm{L}$ of this solution was injected into a Shimadzu GC-2014 model with on-column injector, flame ionization detector (FID) and DB-23 column $(30 \mathrm{~m} \times 0.25 \mathrm{~mm} \times 0.25 \mu \mathrm{m})$. Injector: temperature ramp $40^{\circ} \mathrm{C}$ to $250^{\circ} \mathrm{C}$, drag gas pressure $\left(\mathrm{H}_{2}\right): 3 \mathrm{~mL} / \mathrm{min}$ at $40^{\circ} \mathrm{C}$.

\section{Results and Discussion}

The apolar extract (Bio-oil) extracted from the wet biomass of the microalga Monoraphidium sp. was mixed and characterized, Table 1 follows the physical-chemical properties.

The density of the apolar extract of the microalga Monoraphidium sp. is similar to the density of light fuel oil $\left(0.85 \mathrm{~g} / \mathrm{cm}^{-3}\right)$ [11], however the viscosity of the bio-oil was high (64.56 cSt), authors like Lin's group (2009), reported similar values in apolar extracts of the microalga Chlorella $s p$. and attributed this high viscosity to the presence of saturated fatty acids and also to the presence of complex hydrocarbons such as antioxidants [12].

The acidity index of $32 \mathrm{mg} \mathrm{KOH} / \mathrm{g}$ (acidity of 16\%), similar to other crude oils as is the case of some palm trees and high when compared with refined oils.

Regarding the iodine content, the value of $83 \mathrm{gI}_{2} / 100 \mathrm{~g}$ of sample is lower than the soybean oil iodine index $\left(120-141 \mathrm{gI}_{2} / 100 \mathrm{~g}\right)$, which has a high content of polyunsaturated fatty acids, mainly linoleic. The degree of unsaturation is directly related to oxidative stability, the higher the unsaturated content the lower the oxidation stability of the product.

The lipid profile of the bio-oil extracted from the microalga Monoraphidium sp., determined by gas chromatography, is presented in Table 2. The results showed the following distribution in the lipid profile of the microalga Monoraphidium sp.

Table 1. Physical-chemical characterization of bio-oil.

\begin{tabular}{ccc}
\hline CHARACTERISTICS & UNIT & RESULT \\
\hline Relative Density at $25^{\circ} \mathrm{C}$ & $\mathrm{g} / \mathrm{cm}^{3}$ & 0.86 \\
Kinematic viscosity, $40^{\circ} \mathrm{C}$ & $\mathrm{cSt}$ & 64.56 \\
Acid value, máx & $\mathrm{mg} \mathrm{KOH} / \mathrm{g}$ & 32.00 \\
Iodine value & $\mathrm{gI}_{2} / 100 \mathrm{~g}$ & 83.00 \\
Nitrogen (N) & $\mathrm{wt} \%$ & 2.00 \\
Carbon (C) & $\mathrm{wt} \%$ & 73.70 \\
Hydrogen (H) & $\mathrm{wt} \%$ & 11.40 \\
Sulfur $(\mathrm{S})$ & $\mathrm{wt} \%$ & $<0.30$ \\
Oxygen $(\mathrm{O})$ & $\mathrm{wt} \%$ & 10.30 \\
\hline
\end{tabular}


Table 2. Lipid profile of the bio-oil extracted from the microalga Monoraphidium sp. cultivated in the UFRN-Natal Raceway.

\begin{tabular}{rccc}
\hline & IDENTIFICATION & & $\%$ ÁREA \\
\hline Lauric & C12:0 & SAFA & 0.72 \\
Myristic & C14:0 & SAFA & 5.90 \\
Palmitic & C16:0 & SAFA & 9.33 \\
Palmitoléico & C16:1 & MUFA & 1.23 \\
Stearic & C18:0 & SAFA & 31.74 \\
Oleic & C18:1 & MUFA & 10.51 \\
Linoleic & C18:2 & PUFA & 5.28 \\
Linolenic & C18:3 & PUFA & 17.53 \\
Arachidonic & C20:0 & SAFA & 7.97 \\
Gadoléico & C20:1 & MUFA & 1.55 \\
Beenic & C22:0 & SAFA & 0.53 \\
Erucic & C22:1 & MUFA & 0.71 \\
Lignoceric & C24:0 & SAFA & 2.40 \\
Nervous & C24:1 & MUFA & 5.57 \\
\hline & & & \\
\hline
\end{tabular}

cultivated in the Raceway of UFRN-Natal: content of SAFA $>$ PUFA $>$ MUFA. Noteworthy are the SAFA C18:0 (Stearic), the PUFA C18:3 (Linolenic) MUFA and C18:1 (Oleic).

The results of elemental analysis allowed us to verify that the nitrogen content in the bio-oil extracted is slightly higher than that of petroleum $(0.11 \%-1.7 \%)$. The carbon $(73.7 \%)$ and hydrogen (11.4\%) contents are similar to those found in some types of oils ( $83 \%$ - $86 \%$ carbon and $11 \%-14 \%$ hydrogen) [13]. While the oxygen content is high when compared to the concentrations present in oils $(0.1 \%-2 \%)$, due to the presence of oxygenated compounds like triglycerides and fatty acids.

Simulated distillation of the bio-oil was carried out in order to identify the initial and final boiling temperature and the yield of the main cuts. The results of this analysis were used in the construction of the distillation curve (Figure 3), reported that the initial boiling point (PIE) it was at the temperature $54.7^{\circ} \mathrm{C}$ and the end point (PFE) at $607.3^{\circ} \mathrm{C}$ approximately, $20 \mathrm{wt} \%$ was distilled from $154.2^{\circ} \mathrm{C}-295.4^{\circ} \mathrm{C}$, therefore the yield is favorable for the production of bio-jet fuel (BioQAv). Mendes (2010) in his study of bio-oil extraction from sewage sludge found that about $33 \% \mathrm{~m} / \mathrm{m}$ of the bio-oil sample distilled below $170^{\circ} \mathrm{C}$, $27.2 \% \mathrm{~m} / \mathrm{m}$ distilled between $170^{\circ} \mathrm{C}-370^{\circ} \mathrm{C}$ and about $38.8 \% \mathrm{~m} / \mathrm{m}$ above that temperature [14].

For the production of renewable hydrocarbons two reactions were carried out, the first one under more severe conditions (temperature of $350^{\circ} \mathrm{C}$ and pressure of $3.250 \mathrm{psi})$ and the second under milder conditions $\left(300^{\circ} \mathrm{C}\right.$ and $1.150 \mathrm{psi}$ pressure). In both reactions the same catalyst was used. 
To reach the reaction temperatures it was necessary 1 hour for the reaction at $300^{\circ} \mathrm{C}$ and 1 hour and 15 minutes for the reaction at $350^{\circ} \mathrm{C}$. Also, it was observed the formation of gases which caused an increase in pressure. This behavior is due to the formation of hydrogen, produced by liquid phase reforming reactions of glycerol and also to the formation of gases by hydrocracking reactions. Thus, there is a slight reduction of pressure in the same temperature condition due to the consumption of part of the hydrogen produced. In this reaction hydrogen formation occurs due to the liquid phase reforming of glycerol, formed during the hydrolysis of the triglycerides, and also from the glycerol added propocitally to increase the production of hydrogen in-situ. This hydrogen is consumed in hydrodeoxygenation, hydrocracking and hydrotreatment reactions.

After the reactions were completed, in both cases the formation of two phases was observed: one organic and the other aqueous with catalyst residues.

Table 3 presents the characterization of the organic phase obtained in both reactions in terms of acidity index and iodine number.

The results of Table 2 show that the iodine content in the organic fractions, produced in the two experimental conditions, decreased considerably in relation to the iodine content of the raw material (bio-oil), which was $83 \mathrm{~g}$ of iodine/g of sample, showing the occurrence of hydrogenation of the unsaturated compounds.

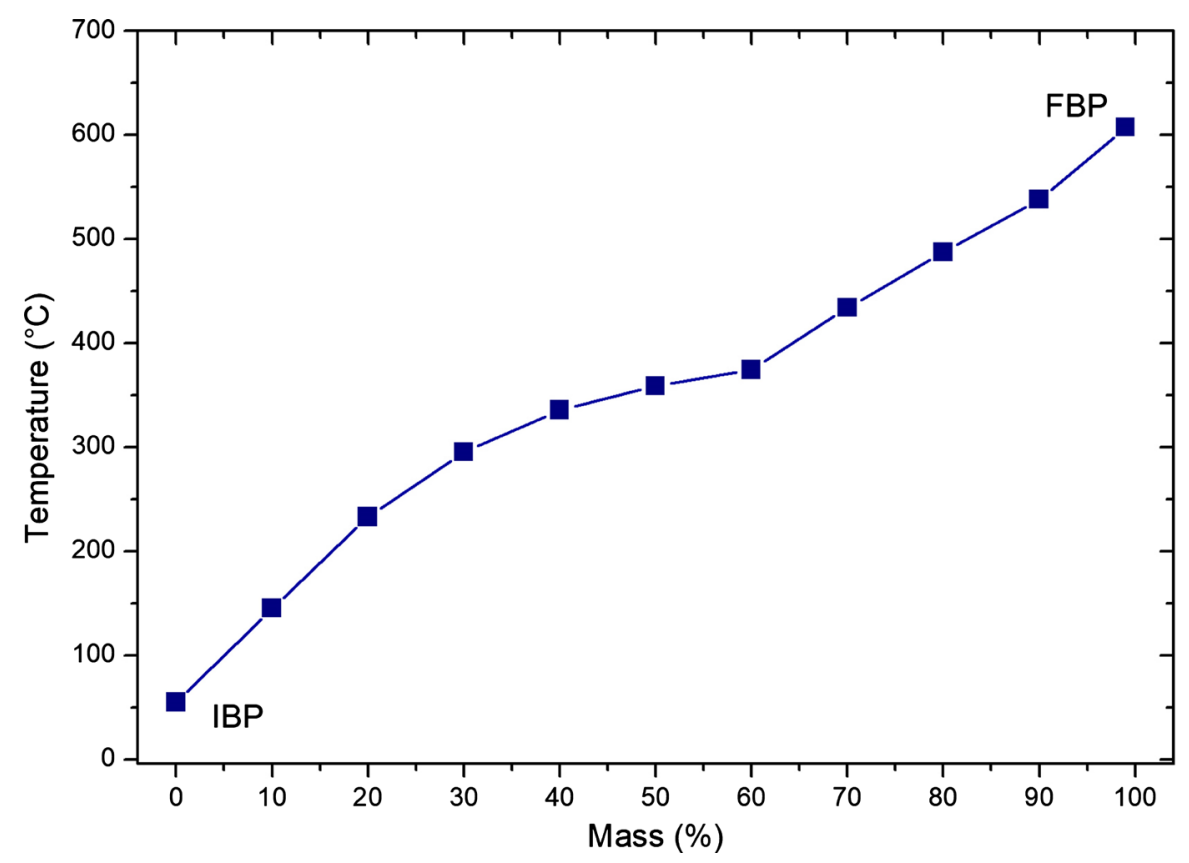

Figure 3. Distillation curve for crude bio-oil.

Table 3. Characterization of the organic phase.

\begin{tabular}{ccc}
\hline Characteristics & Organic phase reaction to $350^{\circ} \mathrm{C}$ & Organic phase reaction to $300^{\circ} \mathrm{C}$ \\
\hline Acid value, $\mathrm{mgKOH} / \mathrm{g}$ & 20.00 & 45.00 \\
Iodine value, $\mathrm{g} / \mathrm{100 \textrm {g }}$ & 5.00 & 12.00 \\
\hline
\end{tabular}


However, it did not become a complete hydrogenation, condition in which the iodine value would reach zero.

In relation to the acidity value, a reduction is observed in the reaction carried out at $350^{\circ} \mathrm{C}$, falling from approximately $15 \%$ in the raw material to $10 \%$ in the organic fraction. This result indicates that there were still free fatty acids that were not converted into hydrocarbons.

In the reaction carried out at $300^{\circ} \mathrm{C}$, the acid content increased from approximately $15 \%$ in the raw material to $22.5 \%$ in the organic fraction. This increase indicates that at that temperature the hydrolysis reaction of the triglycerides predominated, forming free fatty acids, instead of hydrodeoxygenation and hydrocracking reactions for the formation of hydrocarbons.

Figure 4 presents a mass balance of the first reaction, performed at $350^{\circ} \mathrm{C}$.

According to Figure 4, the total mass of product after the bio-oil processing reaction was $225.81 \mathrm{~g}$, with a loss of $48.19 \mathrm{~g}(17.6 \%)$ in relation to the initial mass $(274 \mathrm{~g}$ ) by gases formation. Of the final product $41.73 \%$ correspond to the organic fraction and $58.27 \%$ to the aqueous fraction with catalyst residue.

Figure 5 shows a mass balance of the second reaction, performed at $300^{\circ} \mathrm{C}$.

According to Figure 5, the total mass of product after the bio-oil processing reaction was $249.63 \mathrm{~g}$, with a loss of $24.37 \mathrm{~g}$ (8.89\%) from the initial mass (274 g) by gas formation. Of the final product $35 \%$ corresponds to the organic fraction and $65 \%$ to the aqueous fraction with catalyst residue.

The organic fraction obtained from the bio-oil processing had the following composition: at a temperature of $350^{\circ} \mathrm{C}$ approximately $81.54 \%$ of hydrocarbons, $9.63 \%$ of fatty alcohols and $8.83 \%$ of free fatty acids; At a temperature of $300^{\circ} \mathrm{C}$ approximately $69.37 \%$ of hydrocarbons, $13.54 \%$ of fatty alcohols and $22.58 \%$ of free fatty acids.

The results presented above show that it was possible to achieve a high conversion to hydrocarbons with the catalyst used in the experimental condition of $350^{\circ} \mathrm{C}$. However, at the temperature of $300^{\circ} \mathrm{C}$ the hydrolysis reaction benefited, obtaining a higher content of free fatty acids and lower hydrocarbon yield.

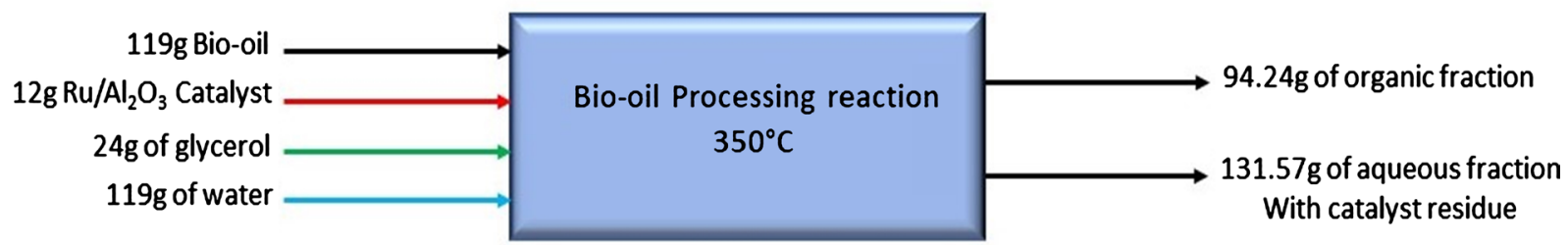

Figure 4. Reaction of Bio-Oil processing at $350^{\circ} \mathrm{C}$ for the production of hydrocarbons.

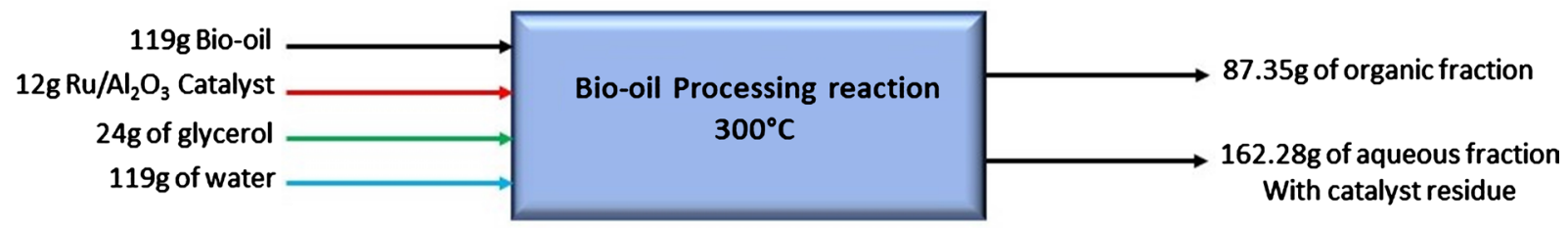

Figure 5. Reaction of Bio-Oil processing at $300^{\circ} \mathrm{C}$ for the production of hydrocarbons. 
Under both conditions the hydrogenation of the unsaturated chains was observed.

\section{Conclusions}

From the wet biomass of the microalga Monoraphidium $s p$., it was possible to extract on average approximately $10 \%$ bio-oil. In the extraction of bio-oil, a mixture of solvents should be used, such as: hexane-ethanol, with the objective of maximizing the extraction of triglycerides and other components with medium polarity, as is the case of fatty acids.

According to the simulated distillation, approximately $35 \%$ of the bio-oil components distil before the final boiling temperature of the medium distillates $\left(300^{\circ} \mathrm{C}\right), 35 \%$ in the diesel range and $15 \%$ above $510^{\circ} \mathrm{C}$. The elemental composition of the bio-oil was quite similar to the composition of the petroleum, except for the oxygen content which was much higher.

The route of the bio-oil processing at $350^{\circ} \mathrm{C}$ proved to be promissory for production of hydrocarbons achieving $81.54 \%$ of conversion.

\section{Acknowledgements}

We thank the National Council for Scientific and Technological Development (CNPq) for the financial support and the GREENTEC Laboratory (UFRJ) for their support in the research.

\section{Conflicts of Interest}

The authors declare no competing financial interest.

\section{Funding Sources}

CNPq (Conselho Nacional de Desenvolvimento Científico e Tecnológico).

\section{References}

[1] Schenk, P.M., Thomas-Hall, S.K., Stephans, E., Marx, U.C., Mussgnug, J.H., Posten, C., Kruse, O. and Hankamer, B. (2008) Second Generation Biofuels: High-Efficiency Microalgae for Biodiesel Production. Bioenergy Research, 1, 20-43.

[2] Li, Z. and Savage, P.E. (2013) Feedstocks for Fuels and Chemicals from Algae: Treatment of Crude Bio-Oil over HZSM-5. Algal Research, 2, 154-163.

[3] Brennan, L. and Owende, P. (2010) Biofuels from Microalgae-A Review of Technologies for Production, Processing, and Extractions of Biofuels and Co-Products. Renewable and Sustainable Energy Reviews, 14, 557-577.

[4] Perlingeiro G, C.A. (2014) Biocombustíveis No Brasil: Fundamentos, Aplicações e Perspectivas. Synergia, 2014, 241-247.

[5] Dieckelmann, G. and Heinz, H.J. (1998) The Basics of Industrial Oleochemistry. A Comprehensive Survey of Selected Technologies Based on Natural Oils and Fats. 1ed. Mulheim/Ruhr, Germany: Peter Pomp Gmbh., 13-37, 177-180.

[6] Ono, Y. (2006) A Survey of the Mechanism in Catalitic Isomerization of Alkanes. Catalysis Today, 81, 3-16. 
[7] Reaume, S.J. and Ellins, N. (2012) Synergistic Effects of Skeletal Issomerization on Oleic and Palmitic Acid Mixtures for the Reduction in Cloud Point of Their Methyl Esters. Energy \& Fuel, 26, 4.514-4.520.

[8] Prates, J. (2006) A diferença entre o H-Bio e o Biodiesel. https://www.biodieselbr.com/noticias/biodiesel/diferenca-hbio-biodiesel-04-07-06

[9] Díaz, G.Ch. (2012) Hidrólise e hidrogenação simultânea (óleo de soja e de sebo bovino)-Efeito do metal Suportado. PhD. Thesis, Federal University of Rio de Janeiro, Rio de Janeiro.

[10] Yoo, C., Jun, S.Y. and Lee, J.Y. (2010) Selection of Microalgae for Lipid Production under High Levels Carbon Dioxide. Bioresource Technology, 101, S71-S74. https://doi.org/10.1016/j.biortech.2009.03.030

[11] Bridgwater, A.V., Czernik, S. and Piskorz, J. (2001) An Overview of Fast Pyrolysis. Progress in Thermochemical Biomass Conversion, 2, 977-997.

[12] Lin, C.-Y. and Li, R.-J. (2009) Fuel Properties of Biodiesel Produced from the Crude Fish oil from the Soapstock of a Marine Fish. Fuel Processing Tecnology, 90, 130-136.

[13] Chaiwong, K.T., Kiatsiriroat, N. and Vorayos, C. (2013) Thararax. Study of Bio-Oil and Bio-Char Production from Algae by Slow Pyrolysis. Biomass and Bioenergy, 56, 600-606.

[14] Mendes, E.R. (2010) Aplicação do processo de pirólise lenta ao lodo de esgoto adicionado de óxido de cálcio e ferro para obtenção de bioóleo Combustível. Master. Thesis, Federal University of Tocantins, Palmas Campus, 91, Brazil.

\section{Abbreviations}

HDO: hydrodeoxygenation;

$\mathrm{Ru} / \mathrm{Al}_{2} \mathrm{O}_{3}$ : ruthenium alumina catalyst;

BioQAv: aviation biokerosene;

$\mathrm{H}_{2}$ :CO: hydrogen and carbon monoxide;

PIE: initial boiling point;

PFE: end point. 